\title{
Strategic Supply Chain Management with the Balanced Scorecard
}

\section{Dobroslav Mollov}

\section{Summary}

The strategic management of the supply chain includes the formulation and implementation of a supply chain strategy as well as the assessment of the results. Undoubtedly, the formulation of a supply chain strategy is part of each of the three levels of strategic planning: corporate, business unit, and functional. For successful strategic management of the supply chain, an integrated approach is needed to link the supply chain strategy with the overall strategic management of the company. It is the Balanced Scorecard which seems to be a suitable and effective tool for this purpose. The Balanced Scorecard focuses on formulating a supply chain strategy, linking it to the corporate vision and turning it into particular actions to achieve the strategic objectives. In this article, a methodology for strategic supply chain management is proposed based on the Balanced Scorecard as an instrument for supply chain strategy formulation and implementation. The methodology consists of twelve steps, each of which is commented in more detail. The article aims at filling the gap identified in the literature devoted to strategic aspects of supply chain management.
Keywords: supply chain, supply chain strategy, strategic supply chain management, Balanced Scorecard

JEL: L21, L25, M10

\section{Introduction}

ccording to CSCMP (2013), "Supply Achain management encompasses the planning and management of all activities involved in sourcing and procurement, conversion, and all logistics management activities. Importantly, it also includes coordination and collaboration with channel partners, which can be suppliers, intermediaries, third party service providers, and customers. In essence, supply chain management integrates supply and demand management within and across companies." Management decisions related to supply chains fall into three categories depending on the time horizon involved: strategic, tactical and operational. Strategic management of the supply chain includes the formulation and implementation of a supply chain strategy as well as the assessment of the implementation results. The supply chain strategy is the plan to achieve the strategic goals of the chain (Mollov, 2017). Rakovska (2013) points out that there is an indisputable relationship between the strategy of the organization of different levels of the company and the supply chain management as means of its realization. The

\footnotetext{
* University of National and World Economy, Sofia, Bulgaria, "International Economics and Politics" Faculty, "International Economic Relations and Business" Department.
} 


\section{Articles}

author states that the compliance between the strategy and the supply chain management has a positive impact on company performance (Rakovska, 2008, 2013). It can be undoubtedly confirmed that the formulation of a supply chain strategy is part of each of the three levels of strategic planning: corporate, business unit and functional. For successful strategic management of the supply chain, an integrated approach is needed to link the supply chain strategy with the overall strategic management of the company (Mollov, 2017). Such an approach is the Balanced Scorecard.

The Balanced Scorecard (BSC) is an approach to strategic management which provides a structured methodology that can help address the shortcomings of traditional strategic management systems. The approach was created in the early 1990s by Robert Kaplan and David Norton. The basic idea set out in the Balanced Scorecard is to translate the strategy into action (Kaplan \& Norton, 1996). The BSC decomposes the vision of the company into particular strategies, each of them described in four points of view, or perspectives, and concretized into specific strategic objectives, critical success factors and cause-and-effect relationships between them, key performance indicators (KPIs) that measure the degree of achievement of strategic objectives and the impact of critical success factors on them, target levels of the $\mathrm{KPIs}$ that enable managers to control the activities aimed at achieving the objectives, and strategic initiatives outlined in an action plan. The BSC is a universal tool for strategic management which can be applied to different companies and industries. One of the possible applications is related to strategic supply chain management.

According to Cohen \& Roussel (2013), there are five core disciplines for top performance of the supply chains and their management: align the supply chain with
Strategic Supply Chain Management with the Balanced

Scorecard

the business strategy, develop an end-toend process architecture, design a highperforming supply chain organization, build the right collaborative model, and use metrics to drive performance. Therefore, performance management is an important part of supply chain strategy and its implementation. It is the Balanced Scorecard which seems to be a suitable and effective tool for binding the supply chain strategy with the performance measurement and management.

The objective of the article is to propose an integrated approach to strategic supply chain management. On the basis of a review of strategic management and supply chain management literature, analysis of business cases, author's experience in business projects and author's reflections and conclusions, a methodology for strategic supply chain management is proposed, based on the Balanced Scorecard as an instrument for supply chain strategy formulation and implementation. The methodology consists of twelve steps in which the Supply Chain Balanced Scorecard Model is constructed. These steps are presented on figure 1.

The twelve steps are identified on the basis of the traditional strategic management process steps, the hierarchical structure of the Balanced Scorecard and the top-down approach which expresses the basic idea of the Balanced Scorecard (i.e. to translate the strategy into action, according to Kaplan \& Norton, 1996) and ensures the vertical consistency of the model. Further down each of the steps is commented in more detail.

\section{Analyzing the external and internal environment}

This analysis aims to reveal the strengths and weaknesses of the company as well as the opportunities the business environment offers and the threats it poses. For the analysis of the internal environment the core competencies 
1. Analyzing the external and internal environment

2. Formulating the vision of the company

3. Formulating the supply chain strategy

4. Defining perspectives

5. Formulating strategic objectives and cause-and-effect relationships between them

6. Identifying critical success factors and cause-and-effect relationships between them

7. Horizontal and vertical alignment

8. Defining key performance indicators

9. Decomposing the Balanced Scorecard

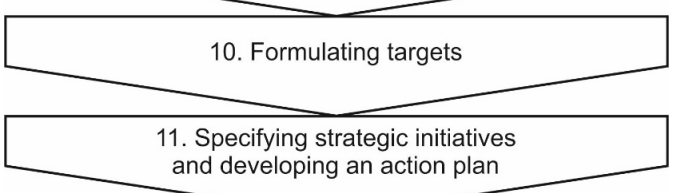

12. Implementing the Balanced Scorecard

Figure 1. Steps in Balanced Scorecard methodology for supply chain management

Source: Adapted from Mollov (2007)

of the company must be identified which are the basis for the competitive advantages of its supply chain. Traditional instruments for analysis can be used, e.g. VRIO framework, value chain analysis, Boston Consulting Group matrix, etc. For the analysis of the external environment the EPIC framework can be used, besides the traditional PESTLE analysis, Porter's five forces and Porter's diamond. The EPIC framework, developed by the Global Supply Chain Institute at the University of Tennessee, USA (Srinivasan et al., 2014; Stank et al., 2014) defines and assesses the business environment factors in countries and regions that influence the efficiency of global supply chain management activities by looking at these factors through the prism of four perspectives: economic $(E)$, political $(\mathrm{P})$, infrastructural $(\mathrm{I})$ and competence (C). The approach measures and determines the level of maturity of geographic regions in terms of their readiness and ability to maintain activities in global supply chains. Each of the four dimensions consists of a set of qualitative and quantitative variables, data from which are derived from official sources such as World Bank, World Economic Forum statistics and reports. The EPIC framework provides the structure for assessing various regions around the globe for supply chain readiness from economic, political, infrastructural and competence perspectives.

\section{Formulating the vision of the company}

When managers look through the prism of the supply chain, they must ask themselves several questions in order to formulate the vision of the company:

- What is the value proposition of the entire supply chain and how it will be delivered to the final customers?

- How can the existing core competencies of supply chain partners be combined, and how can new ones be developed, so that customers can value them?

- What part of value adding processes should the company control and what part of them should it transfer to the partners in the supply chain?

\section{Formulating the supply chain strategy}

The following key elements of the supply chain strategy can be identified (Mollov, 2017):

- Configuration of the supply chain: what will be the structure of the supply chain, 


\section{Articles}

the links between its elements, the participants in the chain and their roles;

- Manufacturing: what products will be manufactured; what will be the number, location, design, and capacity of manufacturing facilities, what manufacturing technologies will be used;

- Procurement and outsourcing: whether the company will produce the materials, components and parts itself or will outsource these activities to the business partners in the chain; the number and type of suppliers; whether the company will use domestic or foreign suppliers;

- Distribution: whether the company will use its own or external distribution channels, if intermediaries or direct distribution channels will be used;

- Inventory management: what will be the number of warehouses and distribution centers and where they will be located; what will their capacity be; whether more stocks will be maintained to ensure stock availability or the stocks will be reduced to reduce costs;

- Transport and logistics: how stocks will move from one stage in the supply chain to another; whether specialized logistics services will be used;

- Supplier and customer relationship management: what type of relationship the company will build with its suppliers and customers; how will it manage and develop the relationships with them;

- Information management: how much data will be collected and what part of the information will be shared with the partners along the chain; what information and communication technologies will be implemented in the chain to help exchange information between partners;

- Sustainability: how the company will meet the expectations of stakeholders; what environmental practices will apply;
Strategic Supply Chain Management with the Balanced Scorecard

how returns in the supply chain will be managed;

- Risk management: what are the risks in the supply chain; what is the probability and impact of each risk; what strategies the company will follow to mitigate risks.

In order to be effective, the supply chain strategy must achieve coherence between the different elements. This requires careful consideration of each element and compliance with the relationships between them.

In the following, a classification of four most popular groups of supply chain strategies is presented. These strategies can serve as a basis for formulating the company's own strategy for its supply chain.

The first group of strategies includes the efficient and responsive supply chains. Fisher (1997) presents two types of supply chains that can also be seen as strategies:

- Physically efficient supply chain suitable for functional products, i.e. products with predictable demand. The primary purpose of this supply chain is to supply predictable demand efficiently at the lowest possible cost;

- Market-responsive supply chain - suitable for innovative products, i.e. products with unpredictable demand. The primary purpose of this supply chain is to respond quickly to unpredictable demand in order to minimize stockouts, forced markdowns, and obsolete inventory.

Hugos (2017) elaborates on this concept and states that for each element of its supply chain strategy, the company has to make choices between two solutions:

- Serving a mass market and competing on the basis of price - supply chain optimized for low cost (efficiency);

- Serving a market segment and competing on the basis of customer service and convenience - supply chain optimized for responsiveness. 


\section{Articles}

Chopra and Meindl (2015) interpret the efficiency and responsiveness of the supply chain as two extremes of a continuous spectrum. Another interpretation of efficiency is given by Skjøtt-Larsen et al. (2007). According to these authors, supply chains can be assessed by means of three performance dimensions: effectiveness, efficiency, and flexibility. This assessment leads to seven different types of supply chains, combining the three dimensions: effective; efficient; flexible; efficient and effective; efficient and flexible; effective and flexible; and efficient, effective and flexible supply chains. These types of supply chains could be considered as supply chain strategies.

The second group includes strategies that are based on the push and pull methods. The two methods are at the heart of the three supply chain strategies identified by SimchiLevi et al. (2003)

- Push-based supply chain strategy: manufacturing and distribution decisions are based on long-term forecasts of the demand;

- Pull-based supply chain strategy: manufacturing and distribution are driven by the demand, they are in line with true customer demand rather than forecast;

- Push-Pull supply chain strategy (a strategy based on the combination of push- and pull- methods): some stages in the supply chain, usually the initial ones, are carried out on the basis of the push method and the others - on the basis of the pull method.

The third group of strategies is based on the study conducted by Naim et al. (1999). This study compares two types of supply chain lean and agile, based on their ability to cope with uncertainty, which includes the variability in the volume of manufacturing and the degree of demand for product diversity by customers. The lean supply chain only manufactures products for which there is real demand from end customers, and delivers them exactly where and when they are needed using a minimum amount of resources (inventories, manufacturing capacity, facilities, people, technologies, information, etc.). The main goal of the lean supply chain is to provide greater value to its customers while limiting the losses called wastes, at the same time. The idea of an agile supply chain is an expression of the company's ability and its supply chain to respond rapidly to changing environmental conditions and unpredictable market demand. Often lean and agile strategies are seen as diametrically opposed paradigms. However, they share the same goal: meeting client demand at the lowest possible cost (Goldsby \& García-Dastugue, 2003). A number of authors point out that these two strategies are not necessarily opposite and that they can be combined in different ways. This leads to the construction of the so-called leagile strategies. Naylor et al. (1999) introduced the term "leagile", which describes the combination of a lean and agile paradigm in a single strategy.

The last group includes the sustainable supply chain strategy. It is based on the "triple bottom line" concept, introduced by Elkington (1997), and manifests itself in adopting and following the social, economic and environmental principles in all elements of the supply chain management. This strategy can be implemented as a combination with other strategies. For example, for the reverse supply chain, which is part of sustainability of supply chains, the lean, agile and leagile approaches can be implemented, according to Wei (2011). The author points that when applied to reverse supply chains, lean approach eliminates all the wastes in the process and helps to achieve the economies of scale in processing and transportation; the agile approach ensures the agility and responsiveness of the return 


\section{Articles}

system; and the leagile approach benefits the company from both costs reduction and increased responsiveness.

\section{Defining perspectives}

The traditional four perspectives can be used as a basis for the strategic supply chain management. The Balanced Scorecard can be modified for the purpose of supply chain management. A new perspective called "Suppliers" can be included, and the "Internal business processes" can be transformed into "Business processes" in order to cover the interface between the company and its customers and suppliers (Figure 2).
Strategic Supply Chain Management with the Balanced Scorecard

\section{Learning and growth perspective}

This perspective identifies the infrastructure the company has to build to secure long-term growth and development. It must answer the question: "To achieve our vision, how will we sustain our ability to change and improve?" (Kaplan \& Norton, 1996). The learning and growth of the company are the result of the interaction of three key factors: human resources, information systems and organizational climate. This perspective relates to the ability of the company to change and be flexible.

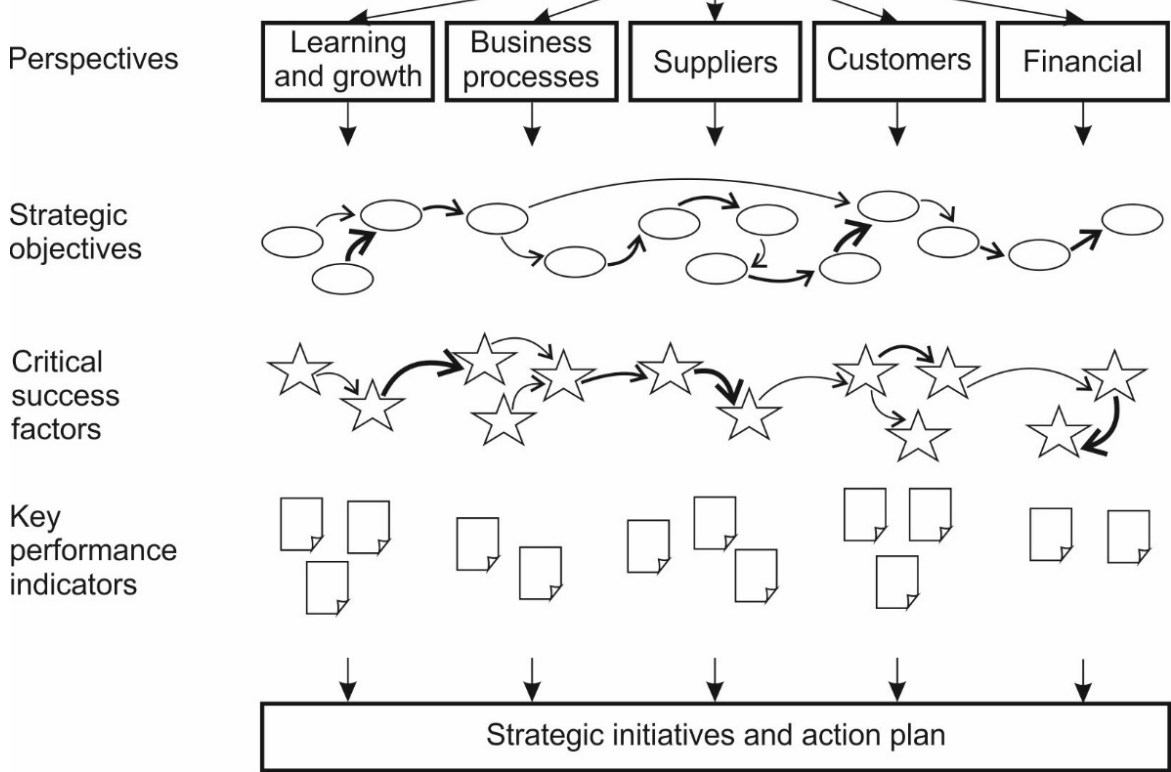

Figure 2. Structure of Supply Chain Balanced Scorecard Model

Source: Author's work 


\section{Articles}

\section{Business processes perspective}

This is the main perspective in the proposed Supply Chain Balanced Scorecard Model, because the integration of business processes is one of the main goals in supply chain management. This is also confirmed by the definition that Lambert (2014) presents about the essence of supply chain management: "Supply chain management is the management of relationships in the network of organizations, from end customers through original suppliers, using key crossfunctional business processes to create value for customers and other stakeholders." The business processes perspective must answer the question: "To satisfy our shareholders and customers, what business processes must we excel at"? (Kaplan \& Norton, 1996). Below some views of the supply chain as a set of business processes are presented.

According to Chopra \& Meindl (2015), the supply chain is a sequence of processes and flows that take place within and between different stages and combine to fill a customer need for a product. The authors present two ways to view the processes performed in a supply chain. According to the first view, the cycle view, the processes in a supply chain can be divided into a series of cycles. Each cycle occurs at the interface between two successive stages of the supply chain. If we consider the supply chain as composed by five stages (supplier, manufacturer, distributor, retailer and customer), all processes in the supply chain can be decomposed into four process cycles: customer order cycle, replenishment cycle, manufacturing cycle, and procurement cycle. Each cycle consists of six subprocesses. It starts with the supplier who markets the product to customers. A buyer then places an order. The order is received by the supplier. The supplier supplies the order. The buyer receives the order. And finally, the buyer may return part of the order, or the entire order (for example, a recycled material) to the supplier or a third party. This cycle of activities then begins again.

Chopra \& Meindl (2015) note that not every supply chain will have all the cycles. As an example we can mention the short food supply chains where the manufacturer, usually a farmer, supplies the products directly to the final customer without intermediaries such as distributors and retailers. In this example the customer order, replenishment and manufacturing cycles form one cycle at the interface between the farmer and the customer. Chopra \& Meindl (2015) mention that the cycle view is useful when considering operational decisions because it specifies the roles and responsibilities of each member of the supply chain and the desired outcome for each process.

The second way to view the processes in a supply chain, presented by Chopra \& Meindl (2015), is the push/pull view. In this view the processes in a supply chain are divided into two categories, depending on whether they are initiated and performed in response to a real customer order (pull processes) or in anticipation of potential customer orders (push processes). Pull processes may also be referred to as reactive processes because they react to actual customer demand, which is known, and they operate in a certain environment. Push processes may also be referred to as speculative processes because they respond to speculated (or forecasted), rather than actual demand, and they operate in an uncertain environment. The push/pull boundary in a supply chain separates push processes from pull processes. Chopra \& Meindl (2015) mention that the push/pull view of the supply chain can be used when considering strategic decisions relating to supply chain design, where the goal is to identify an appropriate push/pull boundary 


\section{Articles}

such that the supply chain can match supply and demand effectively.

In addition, the authors point out that all supply chain processes discussed in the two process views can be classified into three macro processes which manage the flow of information, product and funds required to generate, receive and fulfill a customer request:

- Customer relationship management (CRM): all processes at the interface between the firm and its customers. It aims to generate customer demand and facilitate the placement and tracking of orders. It includes processes such as marketing, pricing, sales, order management, and call center management;

- Internal supply chain management (ISCM): all processes that are internal to the firm. It aims to fulfill demand generated by the CRM process in a timely manner and at the lowest possible cost. It includes the planning of internal production and storage capacity, preparation of demand and supply plans, and fulfillment of actual orders;

- Supplier relationship management (SRM): all processes at the interface between the firm and its suppliers. It aims to arrange for and manage supply sources for various goods and services. It includes the evaluation and selection of suppliers, negotiation of supply terms, and communication regarding new products and orders with suppliers.

Another way to present the business processes in the supply chain are the reference models. One of them is the Supply Chain Operations Reference (SCOR) model. It links business processes, performance metrics, practices, and people skills into a unified structure (APICS, 2017). The SCOR model recognizes six major business processes:
Strategic Supply Chain Management with the Balanced Scorecard

- Plan - the activities associated with developing plans to operate the supply chain;

- Source - the ordering (or scheduling of deliveries) and receipt of goods and services;

- Make - the activities associated with the conversion of materials or creation of the content for services;

- Deliver - the activities related to the creation, maintenance and fulfillment of customer orders;

- Return - the activities concerning the reverse flow of goods;

- Enable - the activities relevant to the management of the supply chain.

For each of the above processes specific process categorizations and process elements exist. The reference model is organized as a hierarchical model with relationships that provide classification of processes. SCOR is a customizable model that can be applied to multiple companies and industries.

Another reference model is the Global Supply Chain Forum (GSCF) model. According to Crandall et al. (2014), this model takes cross-functional and cross-business perspectives to examine the effectiveness of supply chain operations. It includes three elements:

- The supply chain network structure, which consists of the network relationships among business partners across the supply chain;

- The supply chain business processes, which sustain these relationships;

- The associated management components.

The GSCF model embraces eight key business processes as follows: customer relationship management; customer service management; demand management; order fulfillment; manufacturing flow management; supplier relationship management; product development and commercialization; returns 


\section{Articles}

management (Cooper et al., 1997; Lambert et al., 1998; Lambert, 2014). Each business process is composed of strategic and operational subprocesses where supply chain activities are actually performed. These activities include the key elements of planning and control, organization structure, information flows, power structure, leadership, corporate culture, and risk/reward structures (Crandall et al., 2014).

On the basis of the above concepts the following supply chain business processes can be defined:

- Basic processes: sourcing (procurement), production (manufacturing, operations), distribution (delivery and customer service), returns (reverse supply chain);

- Supporting processes: planning, inventory management, logistics management, quality management, risk management, IT management.

\section{Suppliers perspective}

"Suppliers" is the new proposed perspective for the Supply Chain Balanced Scorecard Model. The question to be answered can be formulated as follows: "To satisfy our customers and shareholders, how should our suppliers add value to the final customers?" Its focus is supplier relationship management.

\section{Customers perspective}

This perspective evaluates the company's capabilities to produce quality goods and perform quality services including delivery and after-sales customer service. It must answer the question: "To achieve our vision, how should we appear to our customers?" (Kaplan \& Norton, 1996). Its focus is customer relationship management.

\section{Financial perspective}

The financial perspective is one of the key components of the Balanced Scorecard, because financial results are the main criteria for assessing the current activity of each company. This perspective must answer the question: "To succeed financially, how should we appear to our shareholders?" (Kaplan \& Norton, 1996). It focuses on the collection, analysis and use of timely and accurate financial information.

\section{Formulating strategic objectives and cause-and-effect relationships between them}

The following is a presentation of some strategic objectives for the supply chain strategy that can be defined for each of the five perspectives.

\section{Learning and growth perspective}

The strategic objectives in this perspective are: the improvement of the common knowledge in the supply chain, innovations, and improvement of the core competencies of the supply chain.

Concerning the common knowledge improvement, the concept of metanational companies introduced by Doz et al. (2001) can be widened and transformed into metanational supply chains - supply chains that create new knowledge by sensing, mobilizing and integrating specific knowledge from different parts of the world and turning it into exceptional innovative products overtaking competitors by operationalizing the activities in the company. A major source of competitive advantages for the metanational supply chains is the unique and specific knowledge that is created within the entire chain. Undoubtedly, the building of metanational supply chains requires a high degree of virtual integration and active knowledge sharing between the partners in the chain (Mollov, 2017).

Regarding the innovations, Dittmann (2017) specifies two broad categories of innovations used in supply chains and their management:

- Informational/analytical innovation. 


\section{Articles}

These include: cloud computing, big data, and cognitive analytics to capture, store, analyze, and derive insights from data, disseminating and capturing data generated by the Internet of Things (loT);

- Physical innovation. These are technologies that take a more physical form and they include: drones, driverless vehicles, robotics, smart glasses/ augmented reality, and 3-D printing.

\section{Business processes perspective}

The main strategic objective in this perspective is integration. In order to be successful, the companies in the supply chain need to integrate their processes. Stevens (1989) defines four stages in the supply chain integration process:

- "Base line" - the responsibility for different activities in the supply chain is in separate, almost independent, departments of the company;

- Functional integration - characterized by discrete business functions, each of which is buffered by inventory;

- Internal integration - a comprehensive integrated planning and control system;

- External integration - full supply chain integration, achieved by extending the scope of integration outside the company to embrace suppliers and customers.

In addition, Crandall et al. (2014) define three steps in the integration process. The idea of the authors is to establish a tentative relationship first and then to expand and solidify it as events and results dictate. The three steps are as follows:

- Build interfaces with customers and suppliers;

- Change interfaces to interlaces to make the relationships closer;

- Change interlaces to integrated relationships. The ultimate objective
Strategic Supply Chain Management with the Balanced

Scorecard

is to develop integrated relationships where participants from different companies not only communicate well but also have a sufficiently trusting relationship to collaborate.

A specific aspect of the integration in supply chain is the integration of the forward and reverse supply chain in the so-called closed-loop supply chain.

Another objective is the optimization of costs, time and quality of business processes. The costs present the relationship with the financial perspective, and the time and quality - the relationship with the suppliers and customers perspectives. Regarding the time, the time compression concept can be adopted. According to Beesley (2014), the time compression is an approach to business process improvement in the supply chain. The author points that this approach focuses on how companies use time to deliver a sustainable fast response to customer needs, through business processes that are organized around a strategic time-based focus. Time compression can be achieved using any one or a combination of seven strategies identified by Carter et al. (1994, cited in Beesley, 2014):

- Simplification of the complexity of the processes;

- Integration and improvement of the information flows and linkages in order to create operability and visibility;

- Standardization by using generic best practice processes, standardized components and modules, and information protocols;

- Concurrent working, moving from sequential to parallel working;

- Variance control, monitoring of the processes, early detection of problems and timely corrective actions to avoid quality and waste problems;

- Automation in order to improve the effectiveness and efficiency of entities and activities within the process; 


\section{Articles}

- Resource planning and allocating resources in line with SCM best practice.

The third possible strategic objective in this perspective is supply chain visibility, defined by Heaney (2013) as "the awareness of, and control over, specific information related to product orders and physical shipments, including transport and logistics activities, and the statuses of events and milestones that occur prior to and in-transit". According to the author, the visibility must be enhanced across the following areas: product and shipment; transport and logistics events; supply chain finance and intelligence; enabling dynamic collaborative processes.

\section{Suppliers perspective}

One of the strategic objectives in this perspective is related to the type of relationship the company must develop with each supplier. According to Burt et al. (2010, cited in Badenhorst-Weiss et al., 2016), there are three types of relationships:

- Transactional - a short-term relationship, appropriate for one-off purchases and ongoing transactions;

- Collaborative - characterized by interdependency and the necessity for cooperation, resulting in many benefits for both parties, including achieving a competitive advantage;

- Alliance or partnership-based - it is goal-oriented, the risks and rewards are shared, and long-term benefits are achieved for both partners.

Another strategic objective is the continuous improvement of the suppliers. According to Wisner et al. (2011), both buyers and suppliers must be willing to continuously improve their capabilities in order to meet customer requirements of cost, quality, delivery and technology. Many companies launch initiatives for the improvement of the quality of their suppliers.

A possible approach in this perspective for evaluation of the suppliers is the total cost of ownership (TCO). According to Ellram (2002, cited in Badenhorst-Weiss et al., 2016), TCO is an approach for understanding and managing the true cost of doing business with a particular supplier, of a particular process or of an outsourcing decision. From a supply chain perspective, it is a holistic measurement of all direct and indirect costs, related to the sourcing of all goods and services (Saunders, 2011, cited in Badenhorst-Weiss et al., 2016).

\section{Customers perspective}

The main strategic objective of this perspective is the increase of the value for the final customer. If we consider the supply chain as a value chain, we can claim that the benefits for the customer are created by reducing cost and adding value within each element of the value chain (such as procurement, manufacture, sales and distribution), and at the interface between elements of the value chain (such as between sales and distribution) (Chaffey, 2015). According to Chaffey (2015), in equation form this is:

Another strategic objective is building long-term relationships with customers.

\section{Financial perspective}

The focus of the financial perspective is the return on investment (ROI). According to Crandall et al. (2014), the evaluation of the $\mathrm{ROI}$ for a supply chain requires a project analysis approach, where the effects of individual incremental actions are considered, and both tangible and intangible benefits and costs are considered. The authors specify the following benefits and costs:

- Tangible benefits: reduced inventory, reduced cycle times, improved customer service, improved quality;

- Intangible benefits: integrated flow of 


\section{Articles}

goods and services, faster resolution of problems, match customer wants with products provided, reduced excess capacity along the supply chain, increased knowledge, reduced risk of supply chain disruption;

- Tangible costs: communications, retraining internal employees, restructure supplier network, design customer network, capital investment;

- Indirect costs: meetings required to organize customer and supplier relationships, programs to change internal culture, changes in organization structure, realignment of roles of supply chain participants;

- Intangible costs: loss of confidential information, increased awareness of inequitable treatment among participants, discrepancy between contribution and payoff among participants, legal actions.

For all strategic objectives defined, cause-and-effect relationships between them must be revealed and described. When identifying these relationships, the bottom-up approach should be followed. This means that the objectives of the learning and growth perspective influence the objectives of the business processes perspective, in turn they influence the objectives of the customers and suppliers' perspectives, and finally, they influence the objectives of the financial perspective.

\section{Identifying critical success factors and cause-and-effect relationships between them}

In this step should be defined the factors that lead to the success of the supply chain strategy and have the greatest impact on its performance. They are critical to achieving strategic objectives. Critical success factors have to be classified by priority. In addition, cause-and-effect relationships between them
Strategic Supply Chain Management with the Balanced

Scorecard

must be built up, as well as cause-and-effect relationships between the factors and the objectives that these factors influence.

One of the critical success factors for the improvement of the common knowledge in the supply chain, and mainly in the global supply chain, is the development of transactional culture across the chain, i.e. a culture which accepts intercultural differences, but at the same time emphasizes that it is necessary to agree on them in order to achieve situational "working" cultural convergence (Daneshka, 2016). In order to develop a successful transactional culture, an intercultural competence must be built, i.e. the individual's capability to work successfully in intercultural environment (Daneshka, 2016).

Some examples of critical success factors for the different strategic objectives are presented in table 1.

\section{Horizontal and vertical alignment}

Prior to defining the KPIs, the Balanced Scorecard should be aligned horizontally and vertically, i.e. it must be ascertained whether it is intrinsically connected. Horizontal alignment means that objectives and factors match the respective perspectives in which they are defined, and there is compliance between the company's supply chain strategy and other strategies. Vertical alignment is a check of logic in compliance between the vision, supply chain strategy, strategic objectives and critical success factors. If corrections are needed, they must be performed in this step.

\section{Defining key performance indicators (KPIs)}

KPIs are high-level metrics that are designed to give senior management an overview of how the business is performing, and they measure processes that are critically important to gaining competitive advantage (Cohen \& Roussel, 2013). They measure 


\section{Articles}

the degree of accomplishment of strategic objectives and the degree of influence of critical success factors on them. The following requirements should be considered when defining the KPIs:

- They should be clear, concrete and unambiguously defined;

- Taken together, they should well cover all aspects of strategic objectives and critical success factors;
- They should help to identify the initiatives related to the achievement of the objectives;

- They must be limited in number so that they can be read easily and quickly;

- For qualitative indicators, scales for measurement and evaluation should be defined in advance.

Some examples of KPIs for the different strategic objectives are given in Table 1.

Table 1. Examples of strategic objectives, critical success factors and key performance indicators for the supply chain balanced scorecard

\begin{tabular}{|c|c|c|c|}
\hline Perspective & Strategic objectives & Critical success factors & Key performance indicators \\
\hline \multirow{3}{*}{ Learning and growth } & $\begin{array}{l}\text { - Improvement of the } \\
\text { common knowledge in } \\
\text { the supply chain }\end{array}$ & $\begin{array}{l}\text { - Improvement of the information } \\
\text { exchange and communication } \\
\text { across the supply chain } \\
\text { - Integration of information systems of } \\
\text { the company with its supply chain } \\
\text { partners } \\
\text { - Development of transactional culture } \\
\text { across the supply chain }\end{array}$ & $\begin{array}{l}\text { - Quantity and quality of collected } \\
\text { knowledge } \\
\text { - Percentage of employees which } \\
\text { use different channels for } \\
\text { information exchange } \\
\text { - Number of supply chain training } \\
\text { programs }\end{array}$ \\
\hline & - Innovations & 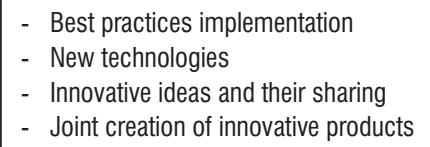 & $\begin{array}{l}\text { - Number of new products } \\
\text { successfully introduced } \\
\text { - Number of new technologies } \\
\text { implemented }\end{array}$ \\
\hline & $\begin{array}{l}\text { - Improvement of the } \\
\text { core competencies of } \\
\text { the supply chain }\end{array}$ & $\begin{array}{l}\text { - Resources and capabilities that } \\
\text { correspond to the VRIO framework }\end{array}$ & - Market share \\
\hline \multirow{3}{*}{ Business processes } & $\begin{array}{l}\text { - Business processes } \\
\text { integration across the } \\
\text { supply chain }\end{array}$ & - Intra-firm integration & - Number of process breaks \\
\hline & $\begin{array}{l}\text { - Business processes } \\
\text { optimization }\end{array}$ & $\begin{array}{l}\text { - } \text { Reduction of costs } \\
\text { - } \text { Time compression } \\
\text { - } \text { Increasing the quality }\end{array}$ & $\begin{array}{l}\text { - Process costs } \\
\text { - Lead time } \\
\text { - Process quality }\end{array}$ \\
\hline & $\begin{array}{l}\text { - Business processes } \\
\text { visibility }\end{array}$ & - Kanban system & $\begin{array}{l}\text { - Number of detected and resolved } \\
\text { problems related to business } \\
\text { processes execution }\end{array}$ \\
\hline \multirow[b]{2}{*}{ Suppliers } & $\begin{array}{l}\text { - Building strategic } \\
\text { alliances with chosen } \\
\text { suppliers }\end{array}$ & $\begin{array}{l}\text { - } \text { Reliable suppliers } \\
\text { - } \text { Mutual trust } \\
\text { - } \text { Aptitude for cooperation }\end{array}$ & $\begin{array}{l}\text { - Number of strategic alliances with } \\
\text { suppliers }\end{array}$ \\
\hline & $\begin{array}{l}\text { - Improvement of the } \\
\text { suppliers }\end{array}$ & $\begin{array}{l}\text { - Willingness for improvement } \\
\text { - Programs for improvement } \\
\text { - Codes of conduct for the suppliers }\end{array}$ & $\begin{array}{l}\text { - TCO } \\
\text { - Number of programs for } \\
\text { improvement implemented } \\
\text { - Evaluation of the results of the } \\
\text { suppliers }\end{array}$ \\
\hline
\end{tabular}




\begin{tabular}{|l|l|l|l|}
\hline Perspective & Strategic objectives & Critical success factors & Key performance indicators \\
\hline \multirow{4}{*}{ Customers } & $\begin{array}{l}- \text { Increasing the value for } \\
\text { the final customer }\end{array}$ & $\begin{array}{l}\text { - Increasing the benefits for the } \\
\text { customers }\end{array}$ & $\begin{array}{l}\text { - Customer value } \\
\text { - Degree of customer satisfaction }\end{array}$ \\
\cline { 2 - 5 } & $\begin{array}{l}\text { - Building long-term } \\
\text { relationships with } \\
\text { customers }\end{array}$ & - Improving customer loyalty & $\begin{array}{l}\text { - Number (or percentage) of new } \\
\text { customers } \\
\text { - Frequency of repeated purchases } \\
\text { - Coefficient of customers retention }\end{array}$ \\
\hline Financial & - Increasing the profits & - Reducing the costs & - ROl and other financial metrics \\
\hline
\end{tabular}

Source: Author's work

\section{Decomposing the Balanced Scorecard}

The Supply Chain Balanced Scorecard can be decomposed according to the organizational structure of the company (departments, divisions) and/or its business processes. Also, specific scorecards for the partners in the supply chain can be constructed. The goal is to see how each organizational unit and/or business process contributes to the vision and strategies of the company, including the supply chain strategy. Compliance between the corporate scorecard and decomposed scorecards must be achieved via horizontal and vertical alignment.

\section{Formulating targets}

For each of the KPls target values must be formulated. The company needs target values in the short and long term so it can measure its development and make timely corrective actions. These values must be consistent with the corporate vision and strategy and must not be contradictory to each other. Therefore, they must also be aligned horizontally and vertically.

\section{Specifying strategic initiatives and developing an action plan}

For each strategic objective, the strategic initiatives to be taken to achieve the target values of its KPls must be formulated. This all is reflected in the initiatives map. Also, initiatives should be ranked by priorities and arranged consistently over time in an action plan. It should include all responsible staff and a timetable for reports.

\section{Implementing the Balanced \\ Scorecard}

In order to complete the process of strategic supply chain management in the company, the Balanced Scorecard must be implemented and integrated into the company's management. The implementation of the Balanced Scorecard is a large-scale project that includes various hierarchical levels in the company and is based on a topdown approach, i.e. it starts with the senior management of the company.

Once the Balanced Scorecard has been successfully implemented, various analyses can be made to improve the system, such as:

- Comparison between scheduled and current status. This analysis calculates the extent to which the objectives and targets are met;

- Analysis of initiatives. This analysis helps to prioritize individual initiatives within the Balanced Scorecard. The analysis calculates the overall effectiveness of individual initiatives related to the main objectives and critical factors.

\section{Conclusion and possible areas for further research}

The literature review indicates that the strategic aspects of supply chain 


\section{Articles}

management are traditionally missing, or are only partially discussed in the specialized literature. At the same time, in today's dynamic business environment the development and implementation of a successful supply chain strategy is an essential element of the performance of all its participants. Therefore, a focus on strategic supply chain management is needed, and an integrated approach is necessary to formulate and realize the supply chain strategy as part of the company's overall strategic management.

The Balanced Scorecard is an approach that can be successfully used to supply chain strategic management. This approach focuses on formulating a supply chain strategy, linking it to the corporate vision and turning it into particular actions to achieve the strategic objectives. Its advantages in terms of strategic supply chain management are as follows:

- It is convenient and easy to understand and implement in practice;

- It makes possible to align the supply chain strategy with other strategies of the company;

- Supply chain strategy is viewed in different perspectives (learning and growth, business processes, suppliers, customers, and financial), enabling an overall assessment of its effectiveness;

- The formulation and implementation of the supply chain strategy becomes real through its decomposition in strategic objectives, critical success factors, strategic initiatives and key performance indicators which measure the achievement of the objectives and the impact of factors;

- It ensures the integrity and consistency of supply chain strategy and initiatives through cause-and-effect relationships between the strategic objectives;

- It enables the communication of the supply chain strategy within all organizational levels of the company;
- It is forward-looking;

- It enables the application of the best practices in the field of strategic supply chain management.

When using the proposed Supply Chain Balanced Scorecard Model, some of its limitations must be taken into account, including:

- The time, efforts and funds necessary to implement the Balanced Scorecard;

- The need to use an information system to collect and analyze data;

- The difficulties related to the alignment of the scorecards of the different participants in the supply chain in order to achieve the chain's common vision;

- The commitment of all employees and the resistance to change.

In spite of the limitations, the Balanced Scorecard seems to be an effective and tool for strategic supply chain management.

Some possible areas for further research could be indicated, for example: the adaptation of the model to services supply chains, global supply chains and short supply chains, the construction of an aggregate model for the entire supply chain, the analysis of the results of the implementation of the model in companies from different branches, and the possible modifications and improvements of the model.

\section{References:}

APICS, 2017. SCOR Version 12.0. [online] http://www.apics.org/apics-for-business/ frameworks/scor12 [accessed June 3, 2019].

Badenhorst-Weiss, J., van Biljon, E., Ambe, I. (editors), 2016. Supply Chain Management: A Balanced Approach. Van Schaik Publishers. Hatfield, Pretoria, RSA.

Beesley, A., 2014. Time Compression in the Supply Chain. In: Waters, D., Rinsler, S. (editors) (2014). Global Logistics: New 


\section{Articles}

Directions in Supply Chain Management. $7^{\text {th }}$ edition. Kogan Page, London, UK.

Burt, D., Petcavage, S., Pinkerton, R., 2010. Supply Management. $8^{\text {th }}$ edition. McGraw-Hill Irwin. Boston, Massachusetts, USA. Cited in: Badenhorst-Weiss, J., van Biljon, E., Ambe, I. (editors) (2016). Supply Chain Management: A Balanced Approach. Van Schaik Publishers. Hatfield, Pretoria, RSA.

Carter, C., Melnyk, P., Handfield, S., 1994. Identifying Sources of Cycle Time Reduction. Quorum, Westport, Connecticut, USA. Cited in: Beesley, A. 2014. Time Compression in the Supply Chain. In: Waters, D., Rinsler, S. (editors) (2014). Global Logistics: New Directions in Supply Chain Management. $7^{\text {th }}$ edition. Kogan Page, London, UK.

Chaffey, D., 2015. Digital Business and E-Commerce Management: Strategy, Implementation and Practice. $6^{\text {th }}$ edition. Pearson Education, Essex, England, UK.

Chopra, S., Meindl, P. 2015. Supply Chain Management: Strategy, Planning, and Operation. $6^{\text {th }}$ edition. Pearson Education Ltd., Edinburgh Gate, Harlow, Essex, England.

Cohen, S., Roussel, J., 2013. Strategic Supply Chain Management: The Five Disciplines for Top Performance. $2^{\text {nd }}$ edition. McGraw-Hill, New York, USA.

Cooper, M., Lambert, D., Pagh, J., 1997. Supply Chain Management: More Than a New Name for Logistics. The International Journal of Logistics Management, Volume 8, Number 1.

Crandall, R. E., Crandall, W. R., Chen, C. C., 2014. Principles of Supply Chain Management. $2^{\text {nd }}$ edition. CRC Press, New York, USA.

CSCMP Supply Chain Management Definitions and Glossary 2013. [online] https://cscmp.org/ CSCMP/Educate/SCM_Definitions_and_ Glossary_of_Terms/CSCMP/Educate/ SCM_Definitions_and_Glossary_of_Terms. aspx? hkey $=608 \overline{7} 9588-\mathrm{f} 65 \mathrm{f}-4 \mathrm{ab} 5-8 \mathrm{c} 4 \mathrm{~b}$ 6878815 ef921 [accessed June 3, 2019].
Strategic Supply Chain Management with the Balanced Scorecard

Daneshka, A., 2016. Intercultural Communication in International Business. Publishing Complex UNWE, Sofia (in Bulgarian).

Dittmann, P., 2017. New Supply Chain Technology. Best Practices. The Application of New Technology in the Physical Supply Chain. A White Paper by the University of Tennessee, Knoxville, Haslam College of Business Supply Chain Management Faculty. [online] https:// haslam.utk.edu/sites/default/files/GSCI $\% 20$ InnovationPaper\%20FIN4-4-17.pdf [accessed June 3, 2019].

Doz, Y., Santos, J., Williamson, P., 2001. From Global to Metanational: How Companies Win in the Knowledge Economy. Harvard Business School Publishing Corp., Boston, USA.

Elkington, J., 1997. Cannibals with Forks: The Triple Bottom Line of 21 st Century Business. Capstone Publishing Ltd., Oxford, UK.

Ellram, L., 2002. Strategic Cost Management in the Supply Chain: A Purchasing and Supply Management Perspective. CAPS Research. Tempe, Arizona, USA. Cited in: BadenhorstWeiss, J., van Biljon, E., Ambe, I. (editors), 2016. Supply Chain Management: A Balanced Approach. Van Schaik Publishers. Hatfield, Pretoria, RSA.

Fisher, M., 1997. What Is the Right Supply Chain for Your Product? Harvard Business Review, Vol. 75, No. 2.

Goldsby, T. J., García-Dastugue, S. J., 2003. The Manufacturing Flow Management Process. The International Journal of Logistics Management, Vol. 14, No. 2.

Heaney, B., 2013. Supply Chain Visibility: A Critical Strategy to Optimize Cost and Service. Aberdeen Group. [online] https://www.gs1.org/ docs/visibility/Supply_Chain_Visibility_ Aberdeen_Report.pdf [accessed June 3, 2019]. Hugos, M. H., 2017. Essentials of Supply Chain Management. $4^{\text {th }}$ edition. John Wiley \& Sons, New Jersey, USA. 


\section{Articles}

Kaplan, R. S., Norton, D. P., 1996. The Balanced Scorecard: Translating Strategy into Action. Harvard Business School Press, Boston, Massachusetts, USA.

Lambert, D. (editor), 2014. Supply Chain Management: Processes, Partnerships, Performance. $4^{\text {th }}$ edition. Supply Chain Management Institute.

Lambert, D., Cooper, M., Pagh, J., 1998. Supply Chain Management: Implementation Issues and Research Opportunities. The International Journal of Logistics Management, Volume 9, Number 2.

Mollov, D., 2007. Knowledge in the Context of Strategic Management of the International Company. Research Papers of UNWE. University Publishing House "Stopanstvo", Sofia, volume II, 2007 (in Bulgarian).

Mollov, D., 2017. Global Supply Chains Concepts and Strategies. $2^{\text {nd }}$ edition. Publishing Complex - UNWE, Sofia (in Bulgarian).

Naim, M., Naylor, J. B., Barlow, J., 1999. Developing Lean and Agile Supply Chains in the UK Housebuilding Industry. IGLC-7, Lean Construction Institute.

Naylor, J. B., Naim, M. M., Berry, D., 1999. Leagility: Integrating the lean and agile manufacturing paradigms in the total supply chain. International Journal of Production Economics, Vol. 62, No. 1-2.

Rakovska, M., 2008. Interaction between business strategy, supply chain management and performance results of manufacturing enterprises. In: Dimitrov, P. (editor) (2008). The logistics in theory and practice. IBIS, Sofia (in Bulgarian). Cited in: Rakovska, M. (2013). Supply Chain Management. Publishing Complex - UNWE, Sofia (in Bulgarian).

Rakovska, M. 2013. Supply Chain Management. Publishing Complex - UNWE, Sofia (in Bulgarian).

Saunders, B., 2011. A Total Cost Approach to Supply Chain Risk Modelling. Brigham Young
University. Provo, Utah, USA. Cited in: Badenhorst-Weiss, J., van Biljon, E., Ambe, I. (editors), 2016. Supply Chain Management: A Balanced Approach. Van Schaik Publishers. Hatfield, Pretoria, RSA.

Simchi-Levi, D., Simchi-Levi, E., Watson, M. (2003). Tactical Planning for Reinventing the Supply Chain. In: Harrison, T. P., Lee, H. L., Neale, J. J. (editors), 2003. The Practice of Supply Chain Management: Where Theory and Application Converge. Springer.

Skjøtt-Larsen, T., Schary, P. B., Mikkola, J. H., Kotzab, H., 2007. Managing the Global Supply Chain. $3^{\text {rd }}$ edition. Copenhagen Business School Press, Denmark.

Srinivasan, M. M., Stank, T. P., Dornier, P.-P., Petersen, K. J., 2014. Global Supply Chains: Evaluating Regions on an EPIC Framework. McGraw-Hill Education, USA.

Stank, T., Burnette, M., Dittmann, P., 2014. Global Supply Chains: A Report by the Supply Chain Management Faculty at the University of Tennessee. The University of Tennessee Global Supply Chain Institute, Knoxville, Tennessee, USA. [online] https://haslam.utk. edu/sites/default/files/GSCI-EPIC-paper.pdf [accessed June 3, 2019].

Stevens, G. C., 1989. Integrating the Supply Chain. International Journal of Physical Distribution \& Materials Management, Vol. 19, No. 8.

Wei, Y., 2011. Reverse Supply Chain Management - explore the feasibility to incorporate forward supply chain strategy into the reverse supply chain in the electronic industry. Master Degree Project. University of Gothenburg, School of Business, Economics and Law. [online] https://gupea.ub.gu.se/ bitstream/2077/26317/1/gupea_2077_26317_1. pdf [accessed June 3, 2019].

Wisner, J. D., Tan, K.-C., Leong, G. K., 2011. Principles of Supply Chain Management: A Balanced Approach. $3^{\text {rd }}$ edition. South-Western Cengage Learning, Ohio, USA. 